\title{
The Influence of Building Information Modelling (BIM) towards Return on Investment (ROI) from the Perspective of Malaysian Developers: A Qualitative Approach
}

\author{
Aryani Ahmad Latiffi, and ${ }^{*} N g$ Hua Tai ${ }^{1}$ \\ ${ }^{1}$ Department of Construction Management, Faculty of Technology Management and Business, Universiti Tun Hussein Onn Malaysia \\ (UTHM), Parit Raja, Johor Darul Takzim, Malaysia.
}

\begin{abstract}
Building Information Modelling (BIM) was introduced in Malaysia in 2007. However, Malaysian developers were reluctant to implement BIM because they could not see the advantages of BIM in monetary terms. This paper aims to determine the impact of BIM towards Return on Investment (ROI) from the developers' perspective. A literature review was carried out to review the linkage between BIM and ROI. The study engaged a qualitative approach and four (4) respondents were selected for preliminary data collection based on their expertise in BIM. Data was collected through face-to-face semi-structured interview sessions and was analysed using a qualitative content analysis technique. The findings show that BIM had impacted on the ROI of both the project and organisation. At present, these findings support the argument that BIM does have an impact on the ROI both positively and negatively. However, the findings prove that BIM is worthy of its pricey initial investment. It is therefore suggested that Malaysian developers to invest in BIM in spite of the pricey initial investment.
\end{abstract}

\section{Introduction}

$\mathrm{BIM}$, is the current process and technology that is said to be able to refine the construction industry. BIM execution is able to furnish several enjoyments to construction projects and all parties involved [1]. One of the advantages of BIM include higher satisfaction of project profitability concerning ROI [2]. ROI is a decision-making tool for appraising suggested expenditures [3].

One of the top five (5) factors hindering the execution of BIM is the insufficient data on ROI of BIM [6] though the BIM adoption rate has increased from $13 \%$ to $54 \%$ in 2016 [4]. These causes reluctancy amongst developers in implementing BIM [5]. The cause is the cost-savings satisfaction such as ROI has not been proven up to the present time [6].

This study aims to determine the impact of BIM on ROI among Malaysian developers. Some research proves that BIM increases the ROI of projects. Nevertheless, the trustworthiness of those results regarding ROI of BIM is questionable [7]. It is because the outcome provided lacking in detail related to the analysis procedure that lessen the reliability, which is why developers are unenthusiastic to execute BIM.

Additionally, there are views that the advantages of BIM directly commensurate to the developers experience level [5]. Which means, the implementation of BIM will be useless if the users are inexperienced [8].

Thus, this study intended to tackle issues that impact BIM in terms of ROI, specifically issues such as the dispute on the authenticity of studies on ROI of BIM from a developer's perspective.

A quick summary of BIM implementation in Malaysia and its linkage with ROI will be explored in the next segment followed by the methods selected, the outcome, and lastly conclusion.

\section{Literature Review}

In Malaysia, BIM is interpreted as a technology for modelling in 3-Dimensions (3D) that corresponds to producing, communicating, analysing as well as applying the digital information models all through a construction project's life-cycle [9]. Many initiatives have been undertaken by the Malaysian Government to implement BIM because the Government is eager to push the adoption of BIM by making it mandatory for all public projects [10].

On top of that, the Construction Industry Development Board (CIDB) has established a BIM Unit Project to prepare BIM Standard Manuals and Guidelines [11] as well as a BIM Roadmap that act as a

\footnotetext{
* Corresponding author: sukinht@gmail.com
} 
benchmark requirement to mandate BIM in Malaysia [11].

BIM has many advantages, namely clash detection, reduces rework, enhancing quality of product and lastly improving ROI. BIM and ROI are co-related as the advantages of BIM directly commensurate the level of experience of developers [5]. The potential savings in a BIM project is approximated between $15 \%$ to $40 \%$ [12]. An additional research also had stipulated that an average ROI gained ranges between $634 \%$ to $1633 \%$ [13]. These findings prove that BIM had positive effects towards ROI.

Still, the ROI of BIM does not necessarily increase [6]. A survey mentioned that $11.9 \%$ of respondents had recorded a decrease of ROI [6]. This understanding is the productivity of BIM is likely to fall low in the starting years of implementation. Thus, it negatively impacts on the overall performance, which results in negative ROI Therefore, it can be deduced that the ROI of BIM does not necessarily increase.

A survey done in the United States of America (USA) and The United Kingdom (UK) shows about $69 \%$ and $80 \%$ of developers who had used BIM had gained a positive ROI [14]. This demonstrates that the perceived ROI from BIM differs in terms levels of expertise [11].

Experienced users are deemed to be most excited with the potential reduction in cost and the ROI gained. It can be deduced that if the level of expertise of developers is high, the perceived ROI gained would be high [5].

\section{Methodology}

A qualitative approach was selected for this study. This approach focussed on the experiences and understanding [15] which enabled researcher to be able to interact with respondents [16]. This approach is beneficial because, though developers in Malaysia are aware of BIM, most of those contacted are hesitant to share 'sensitive' data. Hence, a qualitative approach was chosen.

The tool opted is the qualitative survey, which is about the enquiry of perception [17]. The questions created were for open-ended interviews. The interview sessions allow interviewees to freely express their beliefs related to the subject [16].

On top of that, all selected respondents had experiences and expertise in BIM. All respondents were working as BIM managers. This study served as a prefatory to the understanding of Malaysian developers in BIM and ROI.

The data was analysed qualitatively using a content analysis method. The inceptive phase of analysis emphasised on transcribing the interviewees' answers and summarising them from the raw data [17]. This method included the conversion of data into text, such as data reorganisation into a more manageable, informative database.

\section{Result and Discussion}

This section presents the findings of the study.

\subsection{Respondents}

All four (4) respondents were BIM Managers, representing four (4) different organisations had participated in this study through several assortment to attain the aim of this study. These respondents and organisations were then shortlisted to ensure the data collected are suitable for this study. Table 1 shows the years of experience of the respondents and the organisation they represented.

Table 1. Years of Experience of the Respondents and the Organisation they represented

\begin{tabular}{|c|c|c|}
\hline Organisation & Respondent & $\begin{array}{c}\text { Years of Experience in } \\
\text { BIM }\end{array}$ \\
\hline A & R1 & 2 \\
\hline B & R2 & 7 \\
\hline C & R3 & 7 \\
\hline D & R4 & 4 \\
\hline
\end{tabular}

R1 employed in Organisation A has been using BIM for 2 years. Both R2 and R3, employed in Organisation B and C had used BIM for 7 years and lastly, R4, employed in Organisation D had used BIM for 4 years. These organisations can be further grouped with the number of years of experience of them implementing BIM [14]. Table 2 shows the categorisation of BIM users based on the number of years in implementing BIM.

Table 2. Categorisation of BIM Users based on Number of Years of Implementing BIM.

\begin{tabular}{|c|c|}
\hline Number of Years & Category \\
\hline $1-2$ & BIM Beginner \\
\hline $2-5$ & BIM Moderate \\
\hline More than 5 & BIM Experienced \\
\hline
\end{tabular}

By contrasting data in both tables, Organisation A can be ascribed as a BIM Beginner, both Organisation $\mathrm{B}$ and $\mathrm{C}$ can be ascribed as BIM Experienced and Organisation D can be ascribed as BIM Moderate.

\subsection{The Influence of BIM on ROI ?}

All respondents have an indistinguishable awareness of the BIM and ROI, in which BIM is a coopetition between parties involved, an assimilation of model and information, while ROI is a tool used to appraise the effectiveness of an investment. However, 
R2 further says that ROI is not only used as rudimentary gauge for profit.

"It can also be used to calculate in terms of the golden triangle of the construction industry, namely cost, time and quality."

$\mathrm{R} 2$

R2 further described that the project is considered successful if it can complete within the allocated cost, planned time and quality criteria requested [18].

Thus, in the atmosphere of the Malaysian construction industry, the definition of ROI has been expanded in this study, which is, ROI is not limited to just quantifying the upcoming profit in monetary terms, but ROI can be calculated in terms of cost, time and quality.

Apart from that, R2 further mentioned that the addition of the ROI is dependent on BIM management performance and subsequently, the level of BIM understanding. Table 3 shows the ROI indicator of the organisations

Table 3. ROI indicator of the Organisations.

\begin{tabular}{|c|c|c|c|c|}
\hline Org & Classification & $\begin{array}{c}\text { 1st } \\
\text { Year } \\
\text { ROI }\end{array}$ & $\begin{array}{c}\text { Years of } \\
\text { Execution }\end{array}$ & $\begin{array}{c}\text { Current } \\
\text { ROI }\end{array}$ \\
\hline A & $\begin{array}{c}\text { BIM } \\
\text { Beginner }\end{array}$ & $\downarrow$ & 2 & $\downarrow$ \\
\hline B & $\begin{array}{c}\text { BIM } \\
\text { Experienced }\end{array}$ & $\downarrow$ & 7 & $\uparrow$ \\
\hline C & $\begin{array}{c}\text { BIM } \\
\text { Experienced }\end{array}$ & $\downarrow$ & 7 & $\uparrow$ \\
\hline D & $\begin{array}{c}\text { BIM } \\
\text { Moderate }\end{array}$ & $\downarrow$ & 4 & $\begin{array}{c}\text { Break- } \\
\text { even }\end{array}$ \\
\hline
\end{tabular}

Note: $\downarrow$ indicates reduce; $\uparrow$ indicates increase

According to the findings, Organisation A recorded a reduction in ROI within 2 years of executing BIM. In contrast, both R2 and R3 had disclosed that Organisation $\mathrm{B}$ and $\mathrm{C}$ had seen a slight addition to the current ROI as compared to previous years. The reasons are that both companies fall under BIM experienced as both organisations had been using BIM for 7 years.

"Usually, it will decrease in first few years due to heavy investment made such as hiring professional consultants and training."

$\mathrm{R} 2$

R2 further explained that one of the reasons for the reduction in the starting years of ROI is the cost of hiring professionals to provide training to existing employers [19].

Besides, R3 further stated that their organisation had undergone some failure in BIM projects during the starting years of execution, which resulted in a loss in profit.

"During the first few years, we had suffered from investments and failure of pioneer projects." R3

Some of the reasons for failure include incompetent existing employees in using BIM tools, failure in sustaining BIM processes and an inability to convince other departments to use BIM [20]. R3 explained that, their organisation started using BIM without really understanding it, and that management had learnt through the hard way. R3 further mentioned that the investment, such as hardware and software, are inevitable to implement BIM [21].

"The ROI can be increased when the cost is reduced." The affirmation is confirmed. R4 expressed that Organisation D had recorded a break-even result during its fourth year of execution. R2 informed that BIM positively improves ROI of a project the most during pre-construction stage. The viewpoint is seconded by R4. R4 expressed that BIM able to lessen the cost and time taken during the design stage.

"In our projects, BIM is heavily implemented for coordination purposes. We see the use of BIM in detecting clashes. To date, we are able to see the cost improvement during design stage."

R4

R4 further states that most cost reduction by BIM is through the clash analysis processes during design phase. These clashes are to be solved prior to construction, which can reduce significantly the amount of potential rework [20]. R4's point of view is in line with the affirmation that the costs reduced are more significant and quantifiable during the construction stage [22]. Moreover, with the capability of BIM, construction workers can estimate more accurate amount of material to be used. Thus, materials will be ordered without over-ordering, consequently the cost will be reduced [23].

This finding is true to Jones [24] that ROI will improve persistently as soon as the new investment has become sturdy. Additionally, all respondents conceded that it requires a few years, approximately three (3) to five (5) years, to physically see any advancement in the organisation's ROI.

\section{Conclusion}

Developers do understand BIM and the potential benefits of it. Yet, developers are unwilling to implement BIM. The ROI of an organisation is proven to be impacted by the use of BIM. It can decrease and increase depending on the experience of the organisation.

It is indisputable that the construction industry can be boosted by using BIM. Thus, it can be concluded that developers should implement BIM after its many proven and demonstrated uses and benefits. Therefore, the study on the out-turn of BIM towards ROI is indispensable to encourage and increase the awareness amidst construction parties to execute BIM in the construction industry. Hereafter, studying BIM's ROI from other construction parties' perception are viable and to calculate the exact percentage of the impact itself. 


\section{References}

1. S. Azhar, M. Khalfan, and T. Maqsood, BIM: Now and Beyond, Construction Economics and Building. J. 12, 4 (2015)

2. C. Eastman, L. Ghang, R. Sacks and P. Teicholz, BIM Handbook: A Guide to BIM for Owners, Designers, Engineers, Contractors, and Facility Managers, $3^{\text {rd }}$ Edition United State of America: Wiley (2018)

3. J. Phillips, P. Phillips, and R. Ray, Measuring Leadership Development: Quantify Your Program's Impact and ROI on Organizational Performance, McGraw Hill Professional (2012)

4. NBS, National BIM Report 2016 United Kingdom: RIBA Enterprises Ltd (2016)

5. McGraw Hill Construction, The Business Value of BIM: Getting BIM to the Bottom Line New York, McGraw Hill Companies (2009)

6. B. Becerik-Gerber, and S. Rice, The Perceived Value of BIM in the United State of America, Building Industry Journal of Information Technology in Construction 15 (2010)

7. G. Lee, H. Par, and J. Won, D3 City project: Economic impact of BIM-assisted Design Validation, Automation in Construction 22 (2013)

8. S. Eisenman and P. Borinara, BIM's Impact on Team Performance 45th ASC International Annual Conference, April 1-4, United State of America (2012)

9. CIDB, Construction Industry Transformation Programme 2016 - 2020 Malaysia: CIDB (2016)

10. J. Rogers, H. P. Chong, and C. Preece, Adoption of Building Information Modelling technology (BIM): Perspectives from Malaysian engineering consulting services firms, Engineering Construction \& Architectural Management 22, 4 (2015)

11. A. Ahmad Latiffi, S. Mohd, J. Brahim, Application of Building Information Modeling (BIM) in the Malaysian Construction Industry: A Story of the First Government Project, Applied Mechanics and Material 773 (2015)
12. G. Holness, BIM ASHRAE. J. 48, 8 (2013)

13. S. Azhar, BIM: Trends, Benefits, Risks, and Challenges for the AEC Industry, Leadership and Management in Engineering 11, 3 (2011)

14. McGraw Hill Construction, The Business Value of BIM for Owners. United Kingdom: McGraw Hill Companies (2014)

15. D. Ezzy, Qualitative Analysis, Routledge (2013)

16. G. Parkinson and R. Drislane, Qualitative Research Online dictionary of the Social Sciences (2011)

17. J. A. Smith (Ed), Qualitative psychology: $A$ practical guide to research methods Sage (2015)

18. K. P. Reddy, BIM for Building Owners and Developers, United State of America: Wiley (2011)

19. E. Johansen and F. Shahrin, Challenges in Engaging the Client during the Capture, Translation, Transformation and Delivery of Client Requirements within the BIM Environment, Proceedings from 7th Nordic Conference on Construction Economics and Organisation, June 12-14, Trondheim (2013)

20. A. Ahmad Latiffi and H. T. Ng, Exploring Developers' Understanding on Building Information Modelling (BIM) and Its Impact on Return on Investment (ROI), International Conference on Research and Innovation in Information Systems (ICRIIS), Malaysia (2017)

21. J. R. Jupp, BIM Investment: Understanding Value, Return and Models of Assessment The 38th Australasian Universities of Building Education Association Conference, November 20-23, University of Auckland, New Zealand (2013)

22. K. Barlish, and K. Sullivan, How to Measure Advantages of BIM - A Case Study Approach, Automation in Construction 24 (2012)

23. D. Mitchell, BIM Execution: A 5D Quantity Surveyor's Views on Procurement and Cost Savings, RICS COBRA Conference, September 1012, 2013 New Delhi (2013)

24. L. R. Jones, ROI Analysis: Applying a Private Sector Approach to Public Sector, Prime Journal of Business Administration \& Management 2, (2011) 